\title{
Correlations between dioxin-like and indicators PCBs: Potential consequences for environmental studies involving fish or sediment
}

\author{
M. Babut ${ }^{\mathrm{a},}{ }^{*}$, C. Miege ${ }^{\mathrm{b}}$, B. Villeneuve ${ }^{\mathrm{a}}$, A. Abarnou ${ }^{\mathrm{c}}$, J. Duchemin $^{\mathrm{d}}$, P. Marchand ${ }^{\mathrm{e}}$ and J.F. \\ Narbonne ${ }^{f}$
}

\footnotetext{
${ }^{a}$ Cemagref, UR BELY, 3bis quai Chauveau - CP 220, F-69336 Lyon, France

${ }^{b}$ Cemagref, UR QELY, F-69336 Lyon, France

c IFREMER Département Biogéochimie et Ecotoxicologie, Centre de Brest, BP70, F 29280 Plouzané, France

d Agence de l'Eau Seine-Normandie, DDD Eau et Santé, 21 rue l'Homme-de-Bois, F-14600 Honfleur, France

${ }^{e}$ LABERCA, Ecole Nationale Vétérinaire, Atlanpôle La Chantrerie - BP 50707, F 44307 Nantes, France

${ }^{f}$ LPTC, Bordeaux 1-CNRS, Bât A12, 351 cours de la Libération, F-33405 Talence, France
}

*: Corresponding author : M. Babut, Tel.: +33 4722087 28, email address : marc.babut@cemagref.fr

\begin{abstract}
:
Among the numerous PCB congeners, most of the dioxin-like PCBs (DL-PCBs) need to be characterized by hyphenated techniques. It has been shown in several instances that these congeners are well related to the total PCB content in fish. We examined datasets collected mainly in France, on freshwater and marine fish and sediments. A statistical model linking DL- and indicator PCBs was developed for a dataset composed of freshwater fishes, and proved to predict well DL-PCBs from indicator PCBs in all other fish sets, including marine ones. Type II error rates remained low in almost all fish sets. A similar correlation was observed in sediments. Non-dioxin-like PCBs elicit various adverse effects and represent $95 \%$ of the total PCBs. A European guideline for them is needed; the correlation between DL- and indicator PCBs could help develop this standard in the future.
\end{abstract}

Dioxin-like PCBs in fish and maybe sediments are rather well predicted by indicator PCBs.

Keywords: Dioxin-like PCB; Indicator PCB; Correlations; Fish; Sediment 
Among the numerous PCB congeners, most of the so-called dioxin-like PCBs (DL-PCBs) need to be analysed separately with sophisticated and expensive techniques. It was shown recently that these congeners are fairly related to the total PCB content in fish (Bhavsar et al., 2007a, b). This finding might open the way to simplifying analytical approaches for analysing and assessing the environmental risks of PCBs, provided this relationship was proven to be general. In Europe, a set of 7 congeners, called "indicator PCBs" (iPCBs) are currently used rather than Aroclor ${ }^{\circledR}$ or similar PCB technical mixtures to estimate "total PCBs". Thus, the relationship between this set of congeners and DLPCBs has to be confirmed.

Most of the toxicological properties of DL-PCBs are related to their affinity to the Ah receptor (Safe and Phil, 1990; Safe, 1994), a characteristic these substances share with polychloro-dibenzodioxins (PCDDs) and polychloro-dibenzofurans (PCDFs). This common mode of action lead to the adoption of Toxicity Equivalent Factors (TEF) for each congener, so as to estimate the overall toxicity of PCDDs and similar substances for human beings on the basis of the toxicity of the 2,3,7,8 tetrachlorodibenzo-dioxin (Van Den Berg et al., 1998). Non dioxin-like PCBs, on the other hand, tend to link to other biological receptors. As a consequence, they display other toxicological characteristics. These include neuro-behavorial alterations (Faroon et al., 2000) and a range of endocrine effects related to reproduction (Monosson, 1999; Faroon et al., 2001). To date no common toxicological metrics could be adopted for non-dioxin-like effects of PCBs. Non dioxin-like PCBs are not regulated in foodstuffs in Europe, while dioxins and related compounds are.

Dioxin-like compounds in foodstuffs are a significant concern for European authorities, which issued regulations in order to limit human exposure to these chemicals in 20012002, updated it in 2006 (E.C., 2006a; b) and plan further revisions in 2008-2009. The current regulation states that fish meat should not exceed a level of $8 \mathrm{pg} \cdot \mathrm{g}^{-1}$ for the sum of dioxins, furans and dioxin-like PCBs (WHO-TEQ 1998); dioxins and furans alone should not exceed $4 \mathrm{pg} \cdot \mathrm{g}^{-1}$. This applies to all fish species, except eel, which should not exceed 4 $\mathrm{pg} . \mathrm{g}^{-1}$ for the sum of dioxins and furans, but $12 \mathrm{pg} \cdot \mathrm{g}^{-1}$ when DL-PCBs are accounted for (E.C., 2006a; b).

In this study, we examined various datasets collected mainly in France in order to study the relationships between DL-PCBs and iPCBs. Following Bhavsar et al. (2007b), our purpose is to examine further whether systematic analysis of DL-PCBs in environmental matrices is justified or not.

Materials and Methods

\section{Freshwater fish collection:}

Depending of the location, 3 sets of freshwater fishes (F1 to F3, Table 1) were captured along the Rhone river with nets by professional fishermen or technicians from fish management authorities. The set $\mathrm{F} 1$ is made of fishes collected in the Rhone river around Lyon (France), between Lucey and Vernaison, from Sep. 2005 till Nov., 2006, while in the set F2 fishes were caught in the Rhone further downstream between March and June, 2007. The F3 set is composed of 79 individual fishes caught in the Rhone river in autumn, 2007. The prospected area lies between the French-Swiss border and Lucey, the upstream station in the F1 set. Thus, F3 fishes are not subjected to the same local PCBs sources as most $F 1$ fishes. PCB sources for $F 3$ fishes include essentially unknown historical local sources and atmospheric inputs. A selection was made among the fishes captured, focussing on those living in contact to sediments as well as on piscivorous species. Whole fishes were kept individually at $4{ }^{\circ} \mathrm{C}$ and brought to the laboratories, then freeze dried immediately after reception. Fillet cuttings of a minimum of about $130 \mathrm{~g}$ (fresh weight) per fish were taken and the skin removed, according to European guidelines (E.C., 2006c). 


\section{Marine fish collection:}

The F4 fish samples set is made of 22 composite samples of sea bass, plaice and flounder pooled by size collected along the French coast in Normandy, mainly in the Seine estuary, a known PCB-contaminated area (Abarnou, 2008). Another set (F5) was obtained by sampling various species as composite samples pooled by size in commercial fisheries or imported in France, either along the French coast or from the North-Eastern Atlantic Ocean. These 73 samples include various species: sole, sea bass, plaice, salmon, sardine, red mullet, blue whiting, mackerel, sea bream, tuna, herring, anchovy etc. Samples were kept in the same conditions as above until analysis.

\section{Sediment collection:}

A first set (S1) of surface sediments from 15 locations was sampled with a grab operated from a boat in autumn 2006 in the Rhone river and in a tributary, the Bourbre, in the same area as the $\mathrm{F} 1$ fish subset. 15 core samples were also collected in the Rhone river during the same period. A second set (S2) composed exclusively of surface sediments was obtained in fall 2007. The samples were gathered with a grab operated either from boat or from the river bank, in sedimentation areas, along an upstream-downstream gradient covering the whole course of the Rhone in France.

Sediments were sieved at $2 \mathrm{~mm}$, stored at $-18^{\circ} \mathrm{C}$ and sent to the laboratories.

\section{$P C B, D L-P C B S, P C D D-F$ analysis}

Two different laboratories performed the analyses. Sediments and fishes were homogenized and freeze dried after reception by these laboratories. Quantities of $50 \mathrm{~g}$ of dried sediments or 50-100 g of dried fishes were used.

The first laboratory ${ }^{2}$ analysed both fish and sediments. Soxhlet extractions were performed with a mixture of toluene/ethanol (30/70). USEPA standard 1613 for PCDDs and PCDFs analysis and 1668 for PCB were applied. Analyses were achieved by gas chromatography (Agilent 6890) coupled with high resolution mass spectrometry (Micromass Ultima Waters). Chromatographic separation was achieved with a DB5ms column for PCDDs and PCDFs and with a HT8 column for PCBs.

The second laboratory ${ }^{3}$ analysed only fishes, following Directive 2002/69/EC guidelines for the official control of dioxins and the determination of DL-PCBs in food (E.C., 2002). The extraction was performed in a Dionex ASE 300 device with toluene/acetone, 70:30 $(\mathrm{v} / \mathrm{v})$ mixture. Purification and fractionation encompassed three successive steps, using silica, Florisil and celite/carbon columns. Separation of coplanar (non-ortho) PCBs from non-planar PCBs was achieved on an activated mixture of Florisil/ Carbopack C/Celite 545. Analysis were performed by gas chromatography coupled with high resolution mass spectrometry (HP 6890 GC coupled with JMS 700D, Jeol). Chromatographic separations were achieved on a DB-5MS column.

Concerning quality insurance, both laboratories used surrogates (whose 13C12-1,2,3,4TCDD for the PCDD/Fs, 13C12-PCB111 for PCBs, ... ) to check for analytical recoveries. Uncertainties on concentration results for PCB and PCDD-F analysis are evaluated at $20 \%$. Limits of quantification in sediments range from 0.06 to $12.00 \mathrm{pg} . \mathrm{g}^{-1} \mathrm{DW}$ for PCBs and 0.004 to $0.6 \mathrm{pg} . \mathrm{g}^{-1} \mathrm{DW}$ for PCDD-Fs. In fishes, limits of quantification range from 0.02 to $8 \mathrm{pg} . \mathrm{g}^{-1}$ wet weight (WW) for PCBs and 0.002 to $0.01 \mathrm{pg} \cdot \mathrm{g}^{-1} \mathrm{WW}$ for PCDD-Fs.

TEF, Toxic Equivalent (TEQ) calculation

Though they share the same mode of action, PCDDs, PCDFs and co-planar PCBs do not display the same toxic potency (Van den Berg et al., 2006). The overall toxicity of a mixture of these compounds is commonly expressed as a single number, the Toxic Equivalent (TEQ), obtained by summing individual compounds concentrations weighed by Toxic Equivalent Factors. A first set of TEFs was initially applied by the North Atlantic Treaty Organisation (Kutz et al., 1990; Van Den Berg et al., 1998). Though the World

\footnotetext{
2 CARSO 321, avenue Jean Jaurès, Lyon, France

${ }^{3}$ LABERCA Ecole Nationale Vétérinaire, Atlanpôle La Chantrerie -Nantes, France
} 
Health Organisation (WHO) suggested recently another approach to deriving TEFs, resulting in different TEF values for most congeners (Van den Berg et al., 2006), the European regulation is still based upon 1998 TEFs (E.C., 2006b). The TEQ values used in the present study are calculated on the basis of 1998 TEF.

\section{Statistics}

Our starting hypothesis was that DL-PCBs and iPCBs are correlated. In order to test this hypothesis for fish samples, a two-step approach was applied: (1) determine a statistical model describing the relationship between DL-PCBs' TEQ and iPCBs in a first fish set (i.e. F1), (2) use this model to calculate TEQ of DL-PCBs from iPCBs in the other sets, and then compare predicted and measured TEQ values. For sediment samples, due to the limited number of samples, we applied only linear regression.

Linear regression was used to correlate Log transformed DL-PCBs (expressed as TEQ) and iPCBs. We used Analysis of Covariance (ANCOVA) using XLSTAT 2008 (Addinsoft) to detect differences in slope among species for linear relation between Log transformed DL-PCBs and iPCBs. The ANCOVA method belongs to a larger family of models called GLM (Generalized Linear Models) as do the linear regression and the analysis of variance (ANOVA). The specificity of ANCOVA is that it mixes qualitative and quantitative explanatory variables. In a first step, the ANCOVA tests the assumption of parallelism of slopes of $X$ on $Y$ for all the groups. In a second step, ANCOVA tests the homogeneity of $Y$ intercepts for all the groups.

\section{Results}

Detailed results are provided as supplementary information. For the Rhone river, the fish contamination data presented here were produced in the context of a large diagnosis of fish contamination in the Rhone catchment. The complete database is also available online $e^{4}$.

\section{Fish}

The sums of iPCBs follow either log-normal distributions (sets F3, F5), or no specific distribution pattern (F1, F2, F4). DL-PCBs (expressed as TEQ) as well as total-TEQ values generally follow log-normal distributions, except for both variables in the F2 subset (Table 1). DL-PCBs represent on average $90.2 \%(65-99 \%, F 2)$ to $94 \%(84-99.7 \%, F 3)$ of total TEQs in freshwater fishes. Marine fishes display lower rates, namely an average of $83 \%(71-97 \%)$ for $\mathrm{F} 4$ and $72.4 \%(18-98.5 \%)$ for $\mathrm{F} 5$ fishes, allowing the exploration of the relationships between these variables by regression techniques.

Log transformed DL-PCBs (expressed as TEQ) and iPCBs are linearly correlated in the F1 series after removing 4 outliers, namely specimens caught immediately downstream a known source of PCBs, displaying very high concentrations of either iPCBs or DL-PCBs $(\mathrm{N}=128, \mathrm{R}=0.96, \mathrm{p}<0.0001$; Eq. 1$)$. Note that in this series $\mathrm{DL}-\mathrm{PCB}$ generally represent the main component of the total-TEQ, and that IPCB and the total TEQ content are also strongly correlated ( $R=0.96, p<0.0001$; normality test passed; Eq. 2$)$.

$$
\log T E Q_{D L-P C B}=-1.167( \pm 0.051)+0.932( \pm 0.022) \times \log \sum i P C B
$$

\section{Eq. 1}

$\log T E Q_{t o t}=-1.128( \pm 0.053)+0.929( \pm 0.023) \times \log \sum i P C B$

\section{Eq. 2}

The Eq. 1 model was applied to predict DL-PCBs' TEQ for F2-fishes. Measured and predicted DL-PCBs are linearly correlated (Figure $1 ; \mathrm{N}=143 ; \mathrm{R}=0.98$, intercept $=0.1346$ $( \pm 0.0166)$, slope $=1.0001( \pm 0.0184), p<0.0001 ;$ normality test passed $)$. Ideally, the slope should equal 1 while the intercept should be 0 .

\footnotetext{
${ }^{4}$ http://www.rhone-mediterranee.eaufrance.fr/milieux-continentaux/pollution_PCB/index.php\#donnees
} 
DL-PCBs in F3 are well predicted from iPCB according to the model in Eq. 1 above $(R=0.96, p<0.0001$; slope $0.9812 \pm 0.0328$, intercept $0.1558 \pm 0.0137)$. Again, slope and intercept are close to ideal values and the normality test passed.

The model in Eq. 1 provided also a good prediction of DL-PCBs from iPCBs for F4 samples $(\mathrm{N}=22 ; \mathrm{R}=0.96, \mathrm{p}<0.0001$; slope $1.0125 \pm 0.0594$, intercept $-0.0319 \pm 0.0459$; normality test passed). Total TEQ prediction from iPCBs was also quite as good as TEQ PCB-DL prediction $(R=0.96, p<0.0001$; slope $1.0469 \pm 0.0679$, intercept $-0.0901 \pm$ 0.0521 ; normality test passed).

For F5 fishes, the model in Eq. 1 provided again a good prediction of the toxic equivalency on the basis of iPCBs; the predicted DL-PCB values were strongly correlated to the measured values $(N=73 ; R=0.96, p<0.0001$, intercept $=-0.2298 \pm 0.0252$, slope $=0.9018 \pm 0.0309$, normality test passed).

The same arises with TEQ prediction from iPCBs (Eq. 2) in all sets F2, F3, F4 and F5: regression between predicted and measured TEQ yielded $R$ values of $0.97,0.97,0.96$ and 0.94 respectively, $\mathrm{p}<0.0001$ in all cases. Slopes ranged between 0.90 (F5) and 1.04 (F4) and intercepts between -0.33 and 0.16 .

As the congener 118 was primarily included both in the set of indicators and in the DLPCBs series, the model predicting DL-PCBs from iPCBs (Eq. 1) was adjusted to 6 congeners, as follows:

$$
\log T E Q_{D L-P C B}=-1.062( \pm 0.059)+0.896( \pm 0.026) \times \log \sum i P C B_{6}
$$

\section{Eq. 3}

With $\log \sum i P C B_{6}$ the sum of congeners 28, 52, 101, 138, 153 and 180 concentrations. Because the overall TEQ content is mostly determined by DL-PCBs, a similar model can be established for the total TEQ (Eq. 4)

$$
\left.\log T E Q_{t o t}=-1.025( \pm 0.060)+0.894( \pm 0.027)\right) \times \log \sum i P C B_{6}
$$

\section{Eq. 4}

Eq. 1 and Eq. 2 models (or Eq. 3 and Eq. 4) are general because they are based on a dataset encompassing several species. Therefore, their eventual applicability to particular species raises question about slope differences among species, due to e.g. their feeding regime, lipid content etc.. Assuming that inter-site differences within a given set are not significant, three ANCOVA analyses were performed on F1 to F3 samples subsets in order to test for regression slope differences among species. Subsets were composed of species with more than 10 individuals. Results are reported in Table 2: the ANCOVA models indicate that there was no difference among slopes, except in the F3 set. Barbel's regression slope in this set $(0.69 \pm 0.056)$ seems also different from those in F1 and F2 sets for the same species (1.03 \pm 0.079 and $0.74 \pm 0.095$ respectively). There is no difference among intercepts, except in the F1 set where the slope for the pike perch is lower than the slopes for other species. This could be due to the fact that all the pike perch fishes were youngsters, and displayed low fat contents, whereas individuals from other species were older and generally fatter.

Type I error ("false positives") correspond to samples predicted to exceed the standard which actually do not, whereas Type II ("false negatives") correspond to samples predicted below the standard and actually exceeding it. Type I and type II error rates on predictions of total TEQ, i.e. based on Eq. 2, were determined in fish data series F2, F3, F4 and F5 (Table 3). Because of the reduced sample size, the rates for F4 are only indicative. The type I error rate were $26.2 \%$ and $100 \%$ in the F2 and F3 sets respectively, but the number of samples predicted to exceed $8 \mathrm{pg} . \mathrm{g}^{-1}$ in F3 was rather low ( 8 samples), therefore this error rate would be meaningless. Both types of error rates in the F2 series are calculated on higher numbers of predictions, and are therefore more significant. The type II error rate in the F3 subset remains also very low. 


\section{Sediments}

The sum of iPCBs concentrations for S1 sediment samples ranged from 0.25 to 131.5 $\mu \mathrm{g} \cdot \mathrm{kg}^{-1}$ (dry weight, DW), with a median at $22.6 \mu \mathrm{g} \cdot \mathrm{kg}^{-1}$. DL-PCBs were comprised between 0.054 to $30.5 \mathrm{ng}^{-1}$ (DW), with a median at $4.5 \mathrm{ng} \cdot \mathrm{g}^{-1}$, whereas the sum of PCDD and PCDF concentrations laid between 0.0008 and $1.196 \mathrm{ng}^{-1}$ (DW), with a median of $0.326 \mathrm{ng} \cdot \mathrm{g}^{-1}$.

DL-PCBs and iPCBs were linearly correlated without transformation; nevertheless, the normality test failed, suggesting that the values should be log-transformed. Logtransformed concentrations of DL-PCBs and iPCBs were also correlated (Eq. 5; DL-PCBs expressed as concentrations; $\mathrm{R}=0.96, \mathrm{p}<0.0001)$. iPCBs were also correlated with the sum of PCDDs and PCDFs concentrations.

$$
\log \sum D L-P C B s=-0.685( \pm 0.072)+1.022( \pm 0.052) * \log \sum i P C B s
$$

\section{Eq. 5}

The sum of iPCBs concentrations in S2 sediments ranged from 2.1 to $73 \mu \mathrm{g} \mathrm{kg}^{-1}$ (DW), with a median at $29 \mu \mathrm{g} \cdot \mathrm{kg}^{-1}$. DL-PCBs were comprised between 0.47 to $12.1 \mathrm{ng}^{-\mathrm{g}^{-1}}$ (DW), with a median of $4.2 \mathrm{ng} \cdot \mathrm{g}^{-1}$. The sum of PCDD and PCDF concentrations laid between 0.0565 and $9.2738 \mathrm{ng} \cdot \mathrm{g}^{-1}$ (DW), with a median at $0.698 \mathrm{ng} \cdot \mathrm{g}^{-1}$.

A relationship between $\mathrm{iPCBs}$ and DL-PCBs very similar to the one in S1 can be observed in this series $(N=21, R=0.95 ; p<0.0001$, slope $=0.7127( \pm 0.0508)$, intercept $=-0.7407$ $( \pm 0.0730)$.

\section{Discussion}

\section{Correlations in fish}

The major contribution of DL-PCBs to the total TEQ content in wild fish have already been observed in Europe, for instance in the Netherlands (de Boer et al., 1993; van Leeuwen et al., 2007). A similar feature was also demonstrated in farmed trout throughout France, at concentrations well below the authorized residue level (Marchand et al., 2004). These authors also showed a good correlation between iPCBs and DL-PCBs expressed as TEQ. In a study published in 2007, the French Agency in charge of risk assessment in alimentation (AFSSA) noticed a strong correlation between iPCBs and DL-PCBs, not only in fish ( $r>0.948$ ) but also in other foodstuffs: eggs, milk, poultry (AFSSA, 2007). Some years before, a correlation between specific congeners, in particular the congener 153 and DL-PCB, was evidenced in marine and freshwater fish in the Netherlands (de Boer et al., 1993), and more recently in eels, bream and chub in the Elbe and some tributaries in Germany (Stachel et al., 2007). A large study on fish from the North American Great Lakes, and extended to other datasets, recently reached the same conclusions (Bhavsar et al., 2007b). Thus, this strong correlation between parameters summarising PCB and dioxin/dioxin-like compounds content appears to be a rather common feature, at least in fish. There is less evidence in other biota. Kay et al. (2005) found only a poor correlation in insects at the Kalamazoo Superfund site. Oh et al. (2003) found a correlation between total PCBs and TEQ of DL-PCBs in oysters and mussels along the South Korean coast, with outliers at local point sources. Moreover the PCBs' contribution to the total TEQ was variable, owing to local sources of PCDDs and PCDFs. In a large Mediterranean study, Storelli et al. (2006) could not test such a relationship in cephalopod molluscs, due to DL-PCBs below the quantification limit.

The above statistics on relationships between iPCBs and either DL-PCB or total TEQ in fish may appear somewhat biased, in the sense that congener 118, a non ortho congener, is common to both tested variables. These correlations nevertheless can make sense because the purpose is to predict DL-PCB toxic equivalency, or total TEQ, from less time and resource consuming measurements. Moreover, congener 118 on average represents about $10 \%$ of the total iPCBs (Table 4 ). A study of the relationships between 6 and 7 iPCBs (with and without this congener) in a large array of food items (fish, milk, 
eggs, poultry, beef meat) in France also showed that both variables were strongly correlated, suggesting that congener 118 is not critical in the evaluation of biota contamination by PCBs (AFSSA, 2007). The average contribution of congener 118 to the TEQ content of DL-PCBS in F1 to F5 subsets (Table 4) falls between around $10-15 \%$, except in F5 (24.6\%). This appears consistent with other fish datasets, as discussed by (Bhavsar et al., 2008). Furthermore the sum of concentrations of 6 iPCBs, i.e. without congener 118, is strongly correlated to DL-PCBs expressed as TEQ in F1 samples (logtransformed values, $\mathrm{R}=0.95, \mathrm{p}<0.0001)$. So it can be inferred that the congener 118 is not essential to the evaluation of the overall iPCB content, and that accounting for it in both variables had not significantly biased the relationships.

Testing for eventual differences in regression slopes among species aimed to examine whether the relationship between iPCBs and DL-PCBs is general or not. In the sets F1 to $\mathrm{F} 3$, only one species in one set displays a significant difference. There is no obvious nor simple explanation for this. We note first that the barbel displays this difference in the F3 set, but not in the $F 1$ and $F 2$ ones. F1 and F2 present much wider ranges of concentrations than F3, including for the barbel. Moreover, F3-barbels predicted TEQ values are systematically higher than measured ones. Nevertheless, the hypothesis of an analytical bias should be discarded, as the barbel samples were randomly placed in the analytical series, and no bias appeared for the other species. The model in Eq. 1 seems therefore to correctly predict TEQ values for DL-PCBs from iPCBs in most cases. The unexplained bias observed for one species in one area suggests to use this model with several fish species and extended concentration ranges. The same is true for its variation based on 6 iPCBs.

\section{Predictions accuracy}

The prediction accuracy in fish sets F2, F3, F4 and F5 was tested against the current European management threshold of 8 pg.g $^{-1}$ (E.C., 2006a; b) as an example (Table 4). Measured TEQ in samples erroneously predicted above the threshold of $8 \mathrm{pg}^{-1} \mathrm{~g}^{-1}$ (i.e. type I errors) range between 4.83 and $7.50 \mathrm{pg}^{-1} \mathrm{~g}^{-1}$. Four species are concerned in F2, and 3 in F3. According to the small number of type I samples, no distinct pattern could be distinguished in terms of species or other fish characteristics.

The rate of type II error in the F2 subset corresponds to 2 samples out of 71 , one eel and one barbel. The barbel displays a TEQ value of $12 \mathrm{pg}^{-1} \mathrm{~g}^{-1}$, well above the regulatory limit. For the eel displays a TEQ at $9 \mathrm{pg}^{-1}$ and the lower bound of the measurement confidence interval falls below the regulatory limit. In the meantime, iPCBs sums of concentrations are 54 and $129 \mu \mathrm{g} \mathrm{kg}^{-1}$ respectively, which is, according to Eq. 2, in the confidence interval of the prediction for the eel, but not for the barbel. Unless an undetected analytical error for the barbel, there is no explanation for this gap. Both "false negative" samples in the set F4 are sea basses, with lipid contents of 9 and $17 \%$ (DW) respectively, indicating the fishes were rather old; they were caught in the vicinity of a harbour, suggesting a possible specific PCB source. The only false negative sample in the F5 set is a sardine, with again a measured iPCBs load $\left(92 \mu \mathrm{g}^{-1}\right)$ well below the value corresponding to the measured DL-PCBs. Thus, apart from undetected analytical errors, most of the type II errors in the 4 sets remain unexplained. Type II error rates are rather low, especially in the large size sets F2, F3 and F5. Nevertheless, they are still above the limit recommended by the European Commission for screening methods, i.e. $1 \%$ (E.C. 2006c). Similar error rates were obtained with the model based on 6 iPCBs (Eq. 4). Both types of errors do not have the same consequences in terms of public health or environmental protection. Indeed, a low type II error rate, if the models reported in Eq. 2 or Eq. 4 were used instead of DL-PCBs and PCDDs - PCDFs measurements, would be a strong requirement in terms of environmental or consumers' health protection, as investigations would stop at this stage. Conversely, a high type I error would not have any consequence in terms of environmental or public health protection. Nevertheless, a type I error rate such as that observed in F2 samples suggests to confirm the prediction by specific measurements of DL-PCBs, PCDDs and PCDFs in case of exceedance of a given threshold, for instance the $\mathrm{i}$-PCBs sum corresponding to $8 \mathrm{pg} \cdot \mathrm{g}^{-1} \mathrm{TEQ}$. This corresponds to a value of of $154 \mu \mathrm{g} \cdot \mathrm{kg}^{-1}$ (WW; confidence interval $120-200 \mu \mathrm{g}^{\mathrm{kg}}{ }^{-1}$ ) for 
the sum of 7 iPCBs on the basis of Eq. 2 , or $143 \mu \mathrm{g} . \mathrm{kg}^{-1}$ (WW; confidence interval 124$165 \mu \mathrm{g} \mathrm{kg} \mathrm{kg}^{-1}$ ) for the sum of 6 iPCBs on the basis of Eq. 4 . In a monitoring perspective accordingly, concentrations above e.g. $105 \mu \mathrm{g} . \mathrm{kg}^{-1}$ for the sum of 6 iPCBs could be considered as close to the regulatory limit for dioxins and related compounds, and potentially exceeding it, and DL-PCBs, PCDDs and PCDFs concentrations could be measured accurately.

\section{Correlations in sediments}

Though the observed concentrations of both iPCBs and DL-PCBs are generally lower in surface sediments as compared to core samples in the S1 series, the relationship between both groups obviously does not differ according to their depth. Furthermore, the number of samples was too small to attempt the same approach as for fish, i.e. to predict and evaluate the predictive ability of Eq. 5 .

We find it inappropriate to attempt to calculate TEQ levels in sediments and relate them to iPCBs contamination, for two reasons. First, as a summary of the dioxin-like toxicity, a sediment-TEQ would be relevant if either benthic invertebrates or fishes were concerned. Invertebrates do not have Ah receptors and thus are rather insensitive to dioxin effects (summary in EC, 2001). Furthermore, the congeners present in sediments are not evenly transferred to fish through the food chain, as discussed below. Sediment-TEQ values would therefore neither predict risk for benthic invertebrates nor for fishes.

Differences in PCB congener profiles between sediment and biota have already been shown, e.g. (Ankley, 1992). Kay et al. (2005) showed that the dioxin-like toxic potency differed among trophic levels in the Kalamazoo aquatic food webs, primarily because more chlorinated congeners were enriched in higher trophic levels. To a certain extent, these differences can be explained by considerations of availability. Nevertheless, another explanation holds for the degree of chlorination and the spatial conformation of congeners, the higher chlorine substituted and non planar PCBs showing less chemical and biological availability due to their stronger sorption to sediment, compared to the lower chlorinated and planar PCBs (You et al., 2007) or less ability to metabolize (Froese 1998, Metcalfe 1997 in Kay et al., 2005). For these reasons, it does not seem appropriate to compare the slopes among matrixes, e.g. sediment and fish. Specific models have to be developed and tested for each matrix.

\section{Adverse effects $P C B$ s in a management perspective}

Given that non dioxin-like PCBs represent different modes of action, DL-PCBs as such are not sufficient alone to assess the whole risk to human health generated by the PCBs associated with food (AFSSA, 2007). PCBs have different modes of action. The first mode to have been accurately described involves the Ah receptor. Coplanar congeners, which bind to this receptor as do PCDDs and PCDFs represent about $5 \%$ of the total load of PCBs. Their relative toxicity has been recently reviewed and the respective toxic equivalent factors (TEF) decreased (Van den Berg et al., 2006). Non dioxin-like PCBs bind to several other receptors and may have various adverse effects, including neurotoxicity on embryos (Ribas-Fito et al., 2001). For these congeners, early symptoms appear in foetus exposed in utero, resulting in audiometry impairment. Other primary effects on health are related to sugars and lipids metabolisms, involved in the etiology of diabetes (Codru et al., 2007). Adverse effects on reproduction involve modifications of the hypothalamus-hypophysis-gonads-liver axis which are caused by both dioxin-like and non dioxin-like congeners (Monosson, 1999).

Therefore, a rigorous assessment of the potential impacts of fish or other food items contaminated with PCBs mixtures should involve both non dioxin-like and DL-PCBs. Since (1) DL-PCBs analysis is more difficult and costly than iPCBs analysis, (2) DL-PCBs are well predicted by iPCBs, and (3) non-dioxin like PCBs also induce important toxic effects, DL-PCBs do not need to be measured systematically but could be introduced at the second stage of a tiered approach.

In this perspective, appropriate threshold values for indicator PCBs in fish or other matrices are needed, at least in Europe. 


\section{Conclusion}

Indicator PCBs and DL-PCBs concentrations are well correlated in freshwater fishes from the Rhone river. As DL-PCBs represent the bulk of TEQ in these fishes, iPCBs are also well correlated to the TEQ content in Rhone fishes. The statistical models derived from these fishes proved to be appropriate for describing the correlation in marine fishes, and appear thus very promising, and possibly general. This finding is consistent with other studies performed with different variables, which led nevertheless to similar conclusions (Bhavsar et al., 2007a; Bhavsar et al., 2007b; AFSSA, 2007).

Similar relationships are likely to exist in other biota and should therefore be explored.

Moreover, iPCBs and DL-PCBs are also correlated in bottom sediments in the Rhone river. It is not possible yet to establish whether this relationship is general or not.

iPCBs concentrations remained correlated with TEQ contents after congener 118 removal from the former variable. Moreover, the resulting model (Eq. 4) yielded close proportions of type II errors (false negatives) in most of the tested fish series.

Either the statistical model based on 7 indicator PCBs or its variation based on 6 congeners were shown to have a good predictive ability when used to predict exceedence of the current guideline for dioxin-like compounds $\left(8 \mathrm{pg} . \mathrm{g}^{-1}\right.$ ), with low type II errors rates. Type I error rates could not be assessed accurately in all sets, due to low sample sizes. When the type I error rate was determined, it ranged between 14 and $26 \%$, depending of the statistical model used. Nevertheless, this type of error appears less important from the perspective of consumers' health protection, i.e. if these models were used to predict guideline exceedence.

Non-dioxin like PCBs elicit various adverse effects, including neuro-toxicity on embryos, and effects on reproduction. Therefore, assessing health effects of PCBs cannot rely solely on DL-PCBs. A specific guideline for total PCBs is therefore strongly needed. The correlation between DL- and iPCBs, could help develop this standard and monitor its implementation in the future.

\section{Acknowledgements}

The data used in this study were kindly provided either by various DSVs (Direction des Services Vétérinaires, on behalf of Ministry of Agriculture) and DIREN (Direction Régionale de I'Environnement) in the Rhone catchment, or by DGAL (Direction Générale de I'Alimentation, Ministry of Agriculture) and Agence de I'Eau Seine-Normandie for marine fish. We would like to thank Antonius Snelder and Ashley Tilghman for their reviews and relevant suggestions.

\section{References}

Abarnou A., 2008. Distribution et devenir de contaminants persistants dans les écosystèmes littoraux. Comparaison Manche Ouest-Manche Est. Agence de I'Eau Seine Normandie - IFREMER, Plouzané, p. 118.

AFSSA, 2007. Avis relatif à l'établissement de teneurs maximales pertinentes en polychlorobiphényles qui ne sont pas de type dioxine (PCB "non dioxin-like", PCBNDL) dans divers aliments. Agence Française de Sécurité Santaire des Aliments, Maisons-Alfort, p. 28.

Ankley G.T., 1992. Bioaccumulation of PCBs from sediments by oligochaetes and fishes: comparison of laboratory and field studies. Canadian Journal of Fisheries \& Aquatic Sciences 49, 2080.

Bhavsar S.P., Fletcher, R., Hayton, A., Reiner, E.J., Jackson, D.A., 2007a. Composition of Dioxin-like PCBs in Fish: An Application for Risk Assessment. Environmental Science and Technology, 3096-3102. 
Bhavsar S.P., Hayton, A., Reiner, E.J., Jackson, D.A., 2007b. Estimating Dioxin-like polychlorinated biphenyl Toxic Equivalents from total polychlorinated biphenyl measurements in fish. Environmental Toxicology and Chemistry 26, 1622-1628.

Bhavsar S.P., Hayton, A., Jackson, D.A., 2008. Uncertainty analysis of dioxin-like polychlorinated biphenyls-related Toxic Equivalents in fish. Environmental Toxicology and Chemistry 27, 997-1005.

Codru N., Schymura, M.J., Negoita, S., Rej, R., Carpenter, D.O., 2007. Diabetes in relation to serum levels of polychlorinated biphenyls and chlorinated pesticides in adult native Americans. Environmental Health Perspectives 115, 1442-1447.

de Boer J., Stronck C.J.N., Traag W.A., van der Meer J., 1993. Non-ortho and monoortho substituted chlorobiphenyls and chlorinated dibenzo-p-dioxins and dibenzofurans in marine and freshwater fish and shellfish from the Netherlands. Chemosphere 26, 1823.

E.C., 2002. Commission Directive 2002/69/EC laying down the sampling methods and the methods of analysis for the official control of dioxins and the determination of dioxin-like PCBs in foodstuffs, Official Journal of the European Union, pp. 209/5209/14

E.C., 2006a. Commission Directive 2006/13/EC of 3 February 2006 amending Annexes I and II to Directive 2002/32/EC of the European Parliament and of the Council on undesirable substances in animal feed as regards dioxins and dioxin-like PCBs. Official Journal of the European Union, pp. 32/44-32/53.

E.C., 2006b. Commission Regulation (EC) n० 199/2006 of 3 February 2006 amending Regulation (EC) No 466/2001 setting maximum levels for certain contaminants in foodstuffs as regards dioxins and dioxin-like PCBs. Official Journal of the European Union, pp. 32/34-32/38.

E.C., 2006c. Commission Regulation (EC) $n^{\circ}$ 1883/2006 of 19 December 2006 laying down methods of sampling and analysis for the official control of levels of dioxins and dioxin-like PCBs in certain foodstuffs, 20/12/2006 ed. Official Journal of the European Union, pp. L 364/332 - 364/343

EC, 2001. Canadian Sediment Quality Guidelines for the protection of aquatic life and Canadian Tissue Residues Guidelines for the protection of wildlife consumers of aquatic biota - Polychlorinated Dibenzo-p-dioxins and Polychlorinated Dibenzo-pfurans (PCDD/Fs) - Technical supporting document - Volume I: guideline derivation. Environment Canada, Environmental Quality Branch, , Ottawa, p. 190.

Faroon O., Jones D., De Rosa C., 2000. Effects of polychlorinated biphenyls on the nervous system. Toxicology and Industrial Health 16, 305-333.

Faroon O.M., Keith S., Jones D., De Rosa C., 2001. Effects of polychlorinated biphenyls on development and reproduction. Toxicology and Industrial Health 17, 63-93.

Kay D.P., Blankenship A.L., Coady K.K., Neigh A.M., Zwiernik M.J., Millsap S.D., Strause K., Park C., Bradley P., Newsted J.L., Jones P.D., Giesy J.P., 2005. Differential accumulation of polychlorinated biphenyl congeners in the aquatic food web at the Kalamazoo River superfund site, Michigan. Environmental Science and Technology 39, 5964-5974.

Kutz F.W., Barnes D.G., Bottimore D.P., Greim H., Bretthauer E.W., 1990. The international toxicity equivalency factor (I-TEF) method of risk assessment for complex mixtures of dioxins and related compounds. Chemosphere 20, 751.

Marchand P., Matayron G., Gade C., Le Bizec B., André F., 2004. PCDD/F, dioxin-like and markers PCBs in trouts from french aquaculture. Organohalogen Compounds 66, 1932-1939.

Monosson E., 1999. Reproductive and developmental effects of PCBs in fish: A synthesis of laboratory and field studies. Reviews in Toxicology 3, 25-75.

Oh J.R., Ikonomou M.G., Fernandez M.P., Hong S.H., 2003. PCB and PCDD/F totals, TEQS, and congener patterns in Korean coastal marine environments, 1987, 
1988, 1990, and 1996-1999. Archives of Environmental Contamination and Toxicology 44, 224-236.

Ribas-Fito N., Sala M., Kogevinas M., Sunyer J., 2001. Polychlorinated biphenyls (PCBs) and neurological development in children: A systematic review. Journal of Epidemiology and Community Health 55, 537-546.

Safe S., Phil D., 1990. Polychlorinated biphenyls (PCBs) dibenzo-p-Dioxins (PCDDs), dibenzofurans (PCDFs), and related compounds: environmental and mechanistic considerations which support the development of toxic equivalency factors (TEFs). CRC Critical Reviews in toxicology 21, 51-87.

Safe S.H., 1994. Polychlorinated biphenyls (PCBs): Environmental impact, biochemical and toxic responses, and implications for risk assessment. Critical Reviews in Toxicology 24, 87.

Stachel B., Christoph E.H., Götz R., Herrmann T., Krüger F., Kühn T., Lay J., Löffler J., Päpke O., Reincke H., Schröter-Kermani C., Schwartz R., Steeg E., Stehr D., Uhlig S., Umlauf G., 2007. Dioxins and dioxin-like PCBs in different fish from the river Elbe and its tributaries, Germany. Journal of Hazardous Materials 148, 199.

Storelli M.M., Barone G., D'Addabbo R., Marcotrigiano G.O., 2006. Concentrations and composition of organochlorine contaminants in different species of cephalopod molluscs from the Italian waters (Adriatic Sea). Chemosphere 64, 129-134.

Van Den Berg M., Birnbaum L., Bosveld A.T.C., Brunström B., Cook P., Feeley M., Giesy J.P., Hanberg A., Hasegawa R., Kennedy S.W., Kubiak T., Larsen J.C., Van Leeuwen F.X.R., Liem A.K.D., Nolt C., Peterson R.E., Poellinger L., Safe S., Schrenk D., Tillitt D., Tysklind M., Younes M., Wærn F., Zacharewski T., 1998. Toxic equivalency factors (TEFs) for PCBs, PCDDs, PCDFs for humans and wildlife. Environmental Health Perspectives 106, 775.

Van den Berg M., Birnbaum L.S., Denison M., De Vito M., Farland W., Feeley M., Fiedler H., Hakansson H., Hanberg A., Haws L., Rose M., Safe S., Schrenk D., Tohyama C., Tritscher A., Tuomisto J., Tysklind M., Walker N., Peterson R.E., 2006. The 2005 World Health Organization reevaluation of human and mammalian toxic equivalency factors for dioxins and dioxin-like compounds. Toxicological Sciences 93, 223.

van Leeuwen S.P.J., Leonards P.E.G., Traag W.A., Hoogenboom L.A.P., De Boer J., 2007. Polychlorinated dibenzo-p-dioxins, dibenzofurans and biphenyls in fish from the Netherlands: concentrations, profiles and comparison with DR CALUX $®$ bioassay results. Analytical \& Bioanalytical Chemistry 389, 321-333.

You J., Landrum P.F., Trimble T.A., Lydy M.J., 2007. Availability of Polychlorinated Biphenyls in field-contaminated sediment. Environmental Toxicology and Chemistry 26, 1940-1948. 
Tables and Figures

Index of tables

Table 1 - Summary of fish and molluscs PCB and PCDD-PCDF contamination levels Table 2- ANCOVA results in F1 to F3 subsets

Table 3 - Contribution of congener 118 to iPCBs sum of concentrations and DL-PCBs TEQ

Table 4 - Error rates in TEQ predictions for fishes

Index of Figures

Figure 1 - Relationship between predicted and measured DL-PCBs (logI-TEQ) in the F2 set 


\begin{tabular}{|c|c|c|c|c|c|c|c|c|c|}
\hline \multirow{2}{*}{ Set } & \multirow{2}{*}{$\begin{array}{l}\text { Sample } \\
\text { size }\end{array}$} & \multirow{2}{*}{$\begin{array}{c}\text { Num } \\
\text { ber } \\
\text { of } \\
\text { speci } \\
\text { es }\end{array}$} & \multirow{2}{*}{$\begin{array}{c}\text { Sample } \\
\text { type }\end{array}$} & \multicolumn{2}{|c|}{$\begin{array}{c}i-P C B s\left(\mu g \cdot k g^{-1}\right. \\
W W)\end{array}$} & \multicolumn{2}{|c|}{$\begin{array}{c}D L-P C B s \\
\left(p g \cdot g^{-1} I-T E Q, W W\right)\end{array}$} & \multicolumn{2}{|c|}{$\begin{array}{c}P C D D-P C D F \\
\left(p g \cdot g^{-1} I-T E Q, W W\right)\end{array}$} \\
\hline & & & & median & $\begin{array}{l}\text { standard } \\
\text { deviation }\end{array}$ & median & $\begin{array}{l}\text { standard } \\
\text { deviation }\end{array}$ & median & $\begin{array}{l}\text { standard } \\
\text { deviation }\end{array}$ \\
\hline$\overline{F 1}$ & 128 & 9 & I & 183 & 345 & 9.00 & 17.70 & 0.46 & 1.59 \\
\hline $\mathrm{F} 2$ & 143 & 17 & I & 117 & 613 & 4.50 & 17.60 & 0.27 & 1.44 \\
\hline F3 & 79 & 9 & I & 30 & 73 & 1.40 & 1.72 & 0.07 & 0.11 \\
\hline $\mathrm{F} 4$ & 22 & 3 & $P$ & 27 & 129 & 1.63 & 5.53 & 0.46 & 0.44 \\
\hline F5 & 73 & 33 & $P$ & 6 & 102 & 0.68 & 7.04 & 0.21 & 0.64 \\
\hline
\end{tabular}

Table 1 - Summary of fish and molluscs PCB and PCDD-PCDF contamination

levels

$\mathrm{I}=$ individuals $; \mathrm{P}=$ pooled, by size class 


\begin{tabular}{|l|c|c|c|c|}
\hline Series & Subset size & Number of species & Slopes different? & Intercepts different? \\
\hline F1 & 109 & 6 & No & No \\
F2 & 69 & 5 & No & No \\
F3 & 55 & 3 & Yes & Yes \\
\hline
\end{tabular}

Table 2- ANCOVA results in F1 to F3 subsets

\begin{tabular}{|c|c|c|c|c|c|c|}
\hline Series & $\begin{array}{c}\text { Number of } \\
\text { samples } \\
\text { predicted } \geq 8 \\
\text { pg. } g^{-1}\end{array}$ & $\begin{array}{c}\text { Number of } \\
\text { these samples } \\
\text { actually } \\
<8 \mathrm{pg} . \mathrm{g}^{-1}\end{array}$ & $\begin{array}{c}\text { Type I } \\
\text { error rate }\end{array}$ & $\begin{array}{l}\text { Number } \\
\text { of } \\
\text { samples } \\
\text { predicted } \\
<8 \mathrm{pg} \cdot \mathrm{g}^{-1}\end{array}$ & $\begin{array}{c}\text { Number } \\
\text { of } \\
\text { samples } \\
\text { actually } \\
\geq 8 \mathrm{pg} \cdot \mathrm{g}^{-1}\end{array}$ & $\begin{array}{c}\text { Type II } \\
\text { error rate }\end{array}$ \\
\hline & \multicolumn{6}{|c|}{ a- model based on 7 indicator PCBs (Eq. 2) } \\
\hline F2 & 61 & 16 & 26.2 & 82 & 2 & 2.4 \\
\hline F3 & 8 & 8 & - & 71 & 0 & 0 \\
\hline $\mathrm{F} 4$ & 6 & 2 & - & 16 & 2 & 12.5 \\
\hline \multirow[t]{2}{*}{ F5 } & 2 & 0 & - & 71 & 1 & 1.4 \\
\hline & \multicolumn{6}{|c|}{ b- model based on 6 indicator PCBs (Eq. 4) } \\
\hline $\mathrm{F} 2$ & 62 & 9 & 14.5 & 81 & 2 & 2.5 \\
\hline F3 & 8 & 8 & - & 71 & 0 & 0 \\
\hline $\mathrm{F} 4$ & 6 & 2 & - & 16 & 2 & 12.5 \\
\hline F5 & 1 & 0 & - & 72 & 2 & 2.7 \\
\hline
\end{tabular}

Table 3 - Error rates in TEQ predictions for fishes

\begin{tabular}{|l|l|c|c|c|c|c|}
\hline & & $F 1$ & $F 2$ & $F 3$ & $F 4$ & $F 5$ \\
\hline iPCB & minimum & $0.8 \%$ & $2.6 \%$ & $2.1 \%$ & $11.1 \%$ & $0.3 \%$ \\
& median & $5.1 \%$ & $5.9 \%$ & $5.8 \%$ & $11.9 \%$ & $10.0 \%$ \\
& maximum & $10.1 \%$ & $21.0 \%$ & $13.9 \%$ & $13.6 \%$ & $24.7 \%$ \\
\hline DL-PCB (TEQ) & minimum & $2.8 \%$ & $8.4 \%$ & $9.7 \%$ & $8.5 \%$ & $0.5 \%$ \\
& median & $10.8 \%$ & $15.5 \%$ & $15.4 \%$ & $24.6 \%$ & $10.6 \%$ \\
& maximum & $18.7 \%$ & $48.7 \%$ & $23.7 \%$ & $59.3 \%$ & $36.0 \%$ \\
\hline
\end{tabular}

Table 4 - Contribution of congener 118 to iPCBs sum of concentrations and DLPCBS TEQ 
Figure 1 - Relationship between predicted and measured DL-PCBs (logI-TEQ) in the $F 2$ set 
Environmental Pollution, vol. 157, p. 3451-3456, doi:10.1016/j.envpol.2009.06.016 